REVISTA DE LITERATURA E CULTURA RUSSA

\title{
Textos de Velimir Khlébnikov em tradução anotada
}

\section{Annotated Translation of Texts by Velimir Khlebnikov}

\author{
Autor: Velimir Khlébnikov \\ Tradutor: Ludmila Menezes Zwick \\ Edição: RUS Vol. 11. Nº 15 \\ Data: Junho 2020




\title{
Textos de Velimir Khlébnikov em tradução anotada
}

\author{
Velimir Khlébnikov \\ Tradução de Ludmila Menezes Zwick*
}

Resumo: Estes seis textos de Velimir Khlébnikov, escritos entre 1904 e 1916, expressam sua reverência à natureza e à inventividade, querelam com as gerações passadas e com vozes de autoridade de sua época, clamam pela liberdade dos povos, pela extirpação do conservadorismo instituído e pela vinda do futurismo. 0 primeiro, Deixe-os ler na lápide, trata de suas crenças sobre a natureza e as coisas vivas, e resume, em tom de burla, seus feitos; o segundo, Cerca de cinco ou mais sentidos, trata de uma espécie de teoria da metamorfose de todas as coisas e de suas respectivas percepções pelos sentidos. Em Observações polêmicas de 1913, manifesta-se contra figuras públicas que criticavam o futurismo; em Seu tagarela sem talento!, Khlébnikov critica alguns futuristas, evidenciando que o futurismo era um movimento cheio de nuanças e apenas parcialmente coeso; em Nota autobiográfica, apresenta suas origens e expõe com firmeza alguns de seus posicionamentos, e, em Carta a dois japoneses, estende as mãos à juventude do oriente.
Abstract: These six texts by Velimir Khlebnikov, written between 1904 and 1916, express his reverence for nature and inventiveness, quarrels with past generations and with voices of authority of his time, clamours for the freedom of the people, for the extirpation of the instituted conservatism and for the coming of futurism. The first text, Let them read on the gravestone, deals with his beliefs about nature and living things and summarizes, in burlesque tone, his achievements; the second, On the five-andmore senses, deals with a kind of theory of the metamorphosis of all things and their respective perceptions by the senses. In Polemical Remarks of 1913, he speaks out against public figures who criticized futurism; in You untalented loudmouth!, Khlebnikov criticizes some futurists, showing that futurism was a movement full of nuances and only partially cohesive; in Autobiographical Note, he presents his origins and firmly exposes some of his positions, and in A Letter To Two Japanese he extends his hands to the youth of the East.

Palavras-chave: Velimir Khlébnikov; Natureza; Inventividade; Futurismo;
Posicionamentos

Keywords: Velimir Khlebnikov; Nature; Inventiveness; Futurism; Positions 
Ele não enxergava distinção entre a

[espécie humana e os animais (...)

foi criança a ponto de supor que o seis viesse

[depois do cinco, e o sete depois do seis.

Velimir Khlébnikov

* Mestre em Estética e História da Arte pela Universidade de São

Paulo e doutora em Literatura e

Cultura Russa pela mesma univer-

sidade.

E-mail: apuslynx@gmail.com https://orcid.org/0000-0001-

9873-7243
Em 1903, ainda com o prenome Viktor, Khlébnikov se tornou aluno da Universidade de Kazan, onde escolheu a Faculdade de Física e Matemática. No departamento de matemática ele permaneceria até novembro, quando se transferiu para o departamento de ciências naturais da mesma instituição. Seus pais tiveram uma boa educação e pertenciam a uma linhagem de aristocratas empobrecidos; seu pai, seu grande influenciador, era um destacado botânico e ornitólogo, fundador da primeira reserva estadual na foz do Volga. Tendo testemunhado eventos como a derrota do exército de Antón I. Deníkin no Cáucaso e no norte do Irã, Khlébnikov constatou que a humanidade se oporia à guerra à medida que se unisse à natureza; tal constatação aparece em muitos de seus escritos, desde obras como o poema Ladomir, de 1920, como no texto Observações ornitológicas na Reserva Pavdinsk, de 1911. Neste último ele narra sua experiência na primavera de 1905, quando, com o apoio da Sociedade de Cientistas Naturais de Kazan, ele foi à reserva Pavdinsk, localizada ao longo da encosta leste da porção norte dos Urais centrais, um local que, segundo ele, era notável não apenas pela taiga virgem e extraordinariamente variada, mas também pela quantidade de aves aquáticas migratórias e pela passagem constante de veados e ursos pelas trilhas de salgueiros. Um trecho: "Riachos e arroios são bastante numerosos. Com natureza montês, as águas em geral fluem ruidosamente e colidem com as pedras, espargindo espuma nas margens. No trecho mediano das montanhas há numerosos 


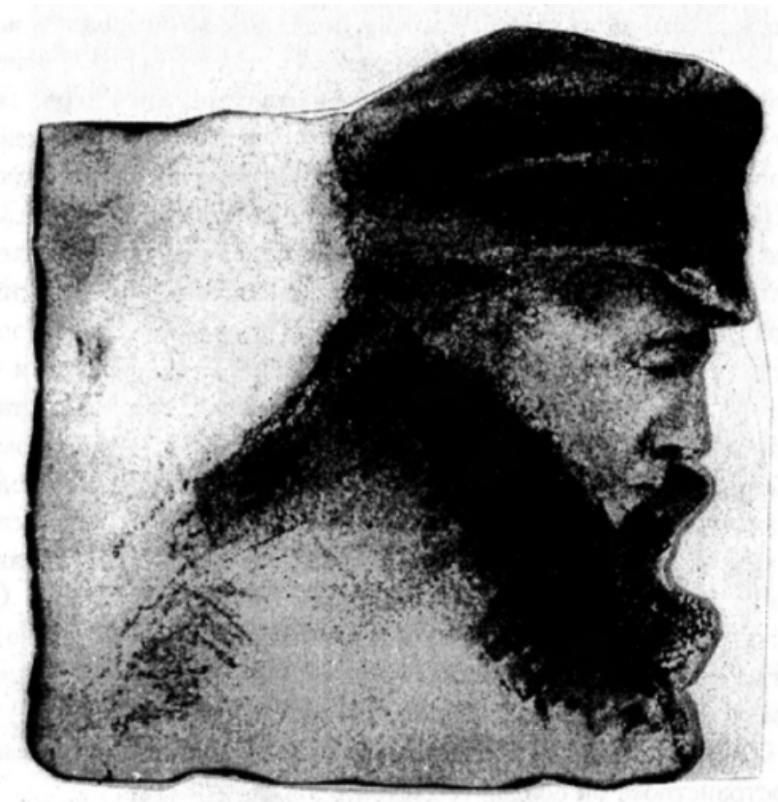

riachos pequenos correndo dentro e fora das rochas. Só é preciso apurar os ouvidos para ouvir aqui e ali seu murmúrio melodioso". ${ }^{1}$

\section{[Deixe-os ler na lápide] ${ }^{2}$}

Deixe-os ler na lápide: ele lutou pela espécie e extirpou de si próprio as aspirações dela. Ele não enxergava distinção entre a espécie humana e os animais e se manteve a favor de estender às nobres espécies animais este mandamento e sua prática: "ama o próximo como a ti mesmo". Ele chamou as indivisíveis e nobres espécies animais de seus "próximos",

Fig. 1. Viktor com um boné de estudante, 1903, de Vera Khlébnikova

Fonte: Coletânea de obras em seis volumes. Ed. por R.V. Dugánov, v. 6, livro 1, p. 8 e assinalou o proveito da utilização de experiências de vida passadas das espécies mais antigas. Ele ainda supôs que beneficiaria a raça humana adotar em seu comportamento algo semelhante à noção das abelhas operárias em uma colmeia, e expressava com frequência que via na noção das abelhas operárias seu próprio ideal pessoal. Ele ergueu o estandarte de amor da Galileia, e estendeu a sombra desse estandarte sobre muitas espécies animais nobres. O coração, a encarnação do ímpeto contemporâneo das sociedades humanas ao progresso, ele não o via no homem principesco, mas no tecido do príncipe $^{3}$ - o nobre bocado de tecido humano encarcerado na caixa

1Khlébnikov, 2005, p. 303.

2 Velimir Khlébnikov não atribuiu título a este texto; daí os colchetes.

3 Uma vez que o tecido cerebral que compõe a mente humana, sendo principesco ou campesino, compõe também a terra, não há divisão entre eles; a nobreza do tecido estaria na mente. Essa associação nada usual do tecido cerebral ao tecido principesco ou campesino relaciona-se à forma adjetivada da escrita de Khlébnikov. Tal ideia surge do contato com a noção de linguagem totalmente eslava de Viacheslav Ivánov, que o estimulou a experimentar a criação de palavras, bem como a ter uma nova atitude em relação às tarefas e métodos da arte literária. Com base no neologismo чернозем (tchernozióm) = черно- + земля (negro + solo), Khlébnikov forma o neologismo terramental, мыслезем (myslezióm) = мысленный + земля, que conota a humanização da natureza, o crescimento constante da substância mental na Terra, correspondendo ao conceito de noosfera, que se difundiria entre os anos de 1920-1930 nos escritos de Vladímir Vernádski (1863-1945), Édouard Le 


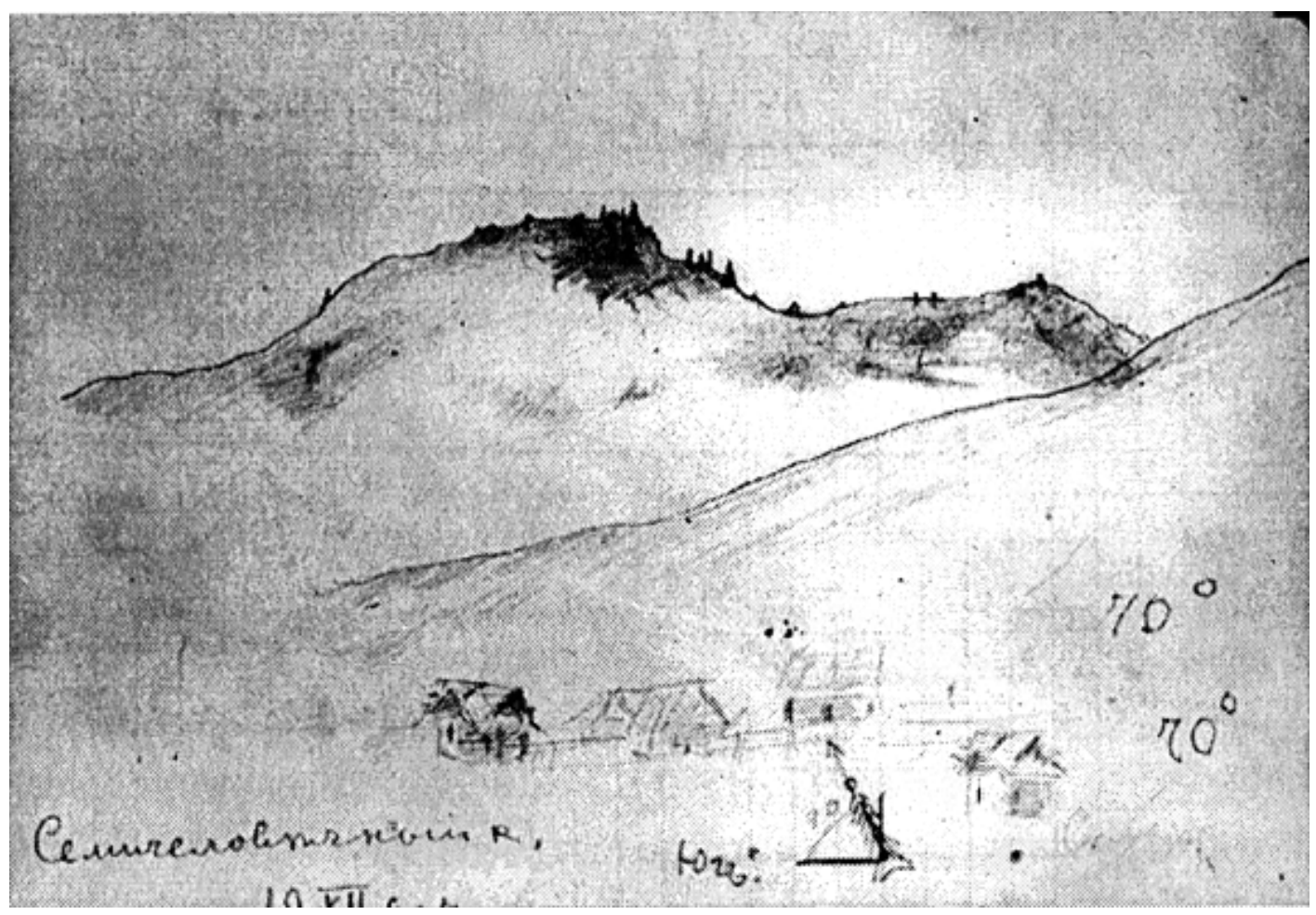

Fig. 2. Paisagem dos Urais em 10 de julho de 1905, de Velimir Khlébnikov.

Fonte: Coletânea de obras em seis volumes. Ed. por R.V. Dugánov, v. 6, livro 1, p. 307-308.

de cálcio do crânio. Ele foi inspirado ao sonho de ser um profeta e um grande intérprete do tecido principesco, e apenas dele. Antevendo sua vontade, com um único ímpeto de seu próprio osso, carne e sangue, ele sonhava com o decréscimo da posição $\varepsilon / \rho$, onde $\varepsilon$ - é igual à massa de tecido principesco, e $\rho$ - é igual à massa de tecido campesino, no que lhe dizia respeito. Ele sonhava com o futuro ${ }^{4}$ distante, o globo da Terra vindoura,

Roy (1870-1954) e Teilhard de Chardin (1881-1955). A afeição à terra semelhante à constituição do homem também figura em textos como "O destino encerrou o sonho com um bocejo..." (Khlébnikov, 2002, p. 273). (Nota baseada na edição russa, doravante mencionada como N. da E.)

4 De acordo com o raciocínio do cientista leto-alemão W. Ostwald (1853-1932), químico e filósofo que influenciou Khlébnikov como estudante em Kazan por meio da obra A filosofia da natureza (São Petersburgo, 1903), a capacidade de antever o futuro seria a mais essencial das propriedades humanas, pois não temos poder algum sobre o passado, apenas sobre 0 futuro; por essa razão, até os problemas mais elevados e abstratos, em todas as áreas da ciência, precisam ser vistos pela via da confiante contemplação do futuro: "[...] o berço da criatividade é o futuro. De lá sopra o vento da palavra dos deuses" (Khlébnikov, 2000, p. 8). (N. da E.) 
Ludmila Menezes Zwick

Irbir una

yoyra.

youm noy
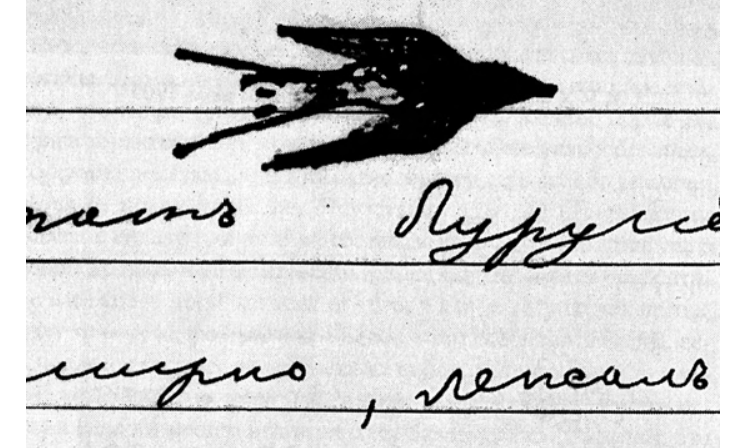

s cects fram n

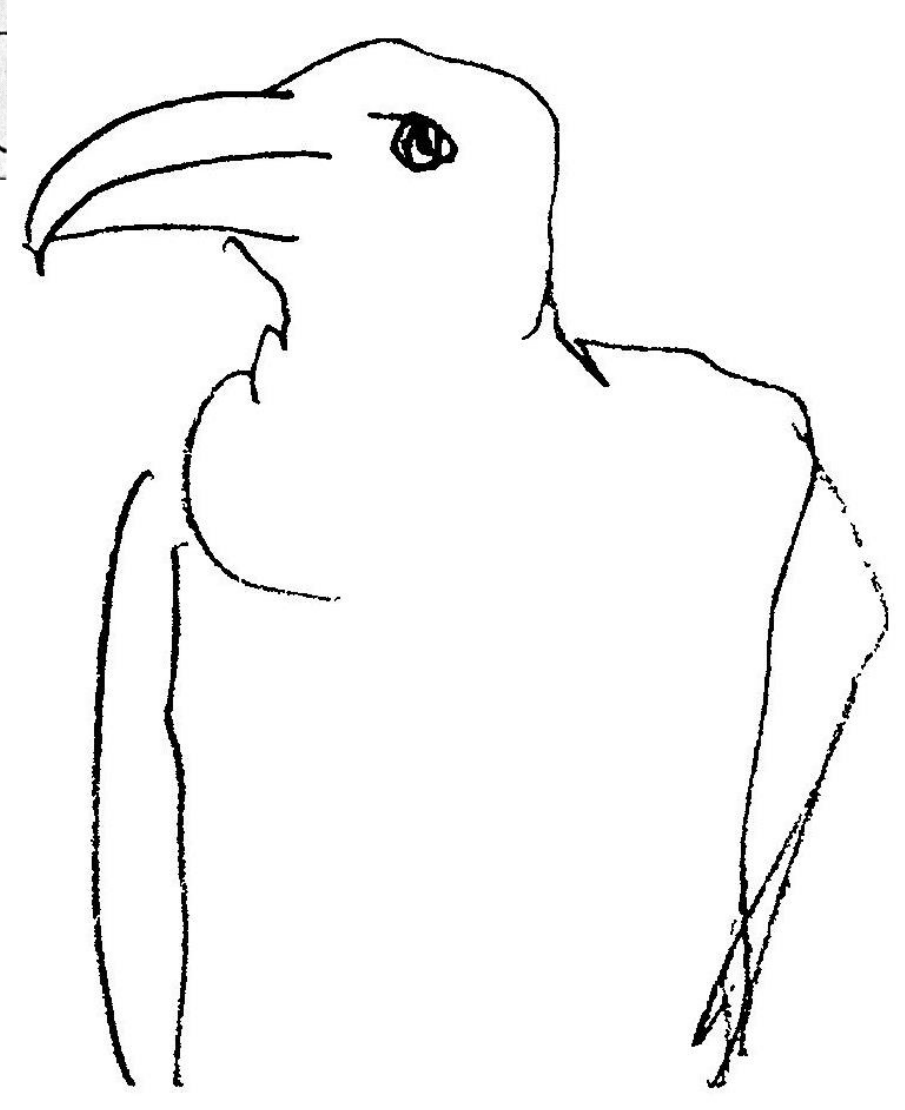

194 
Textos de Velimir Khlébnikov em tradução anotada

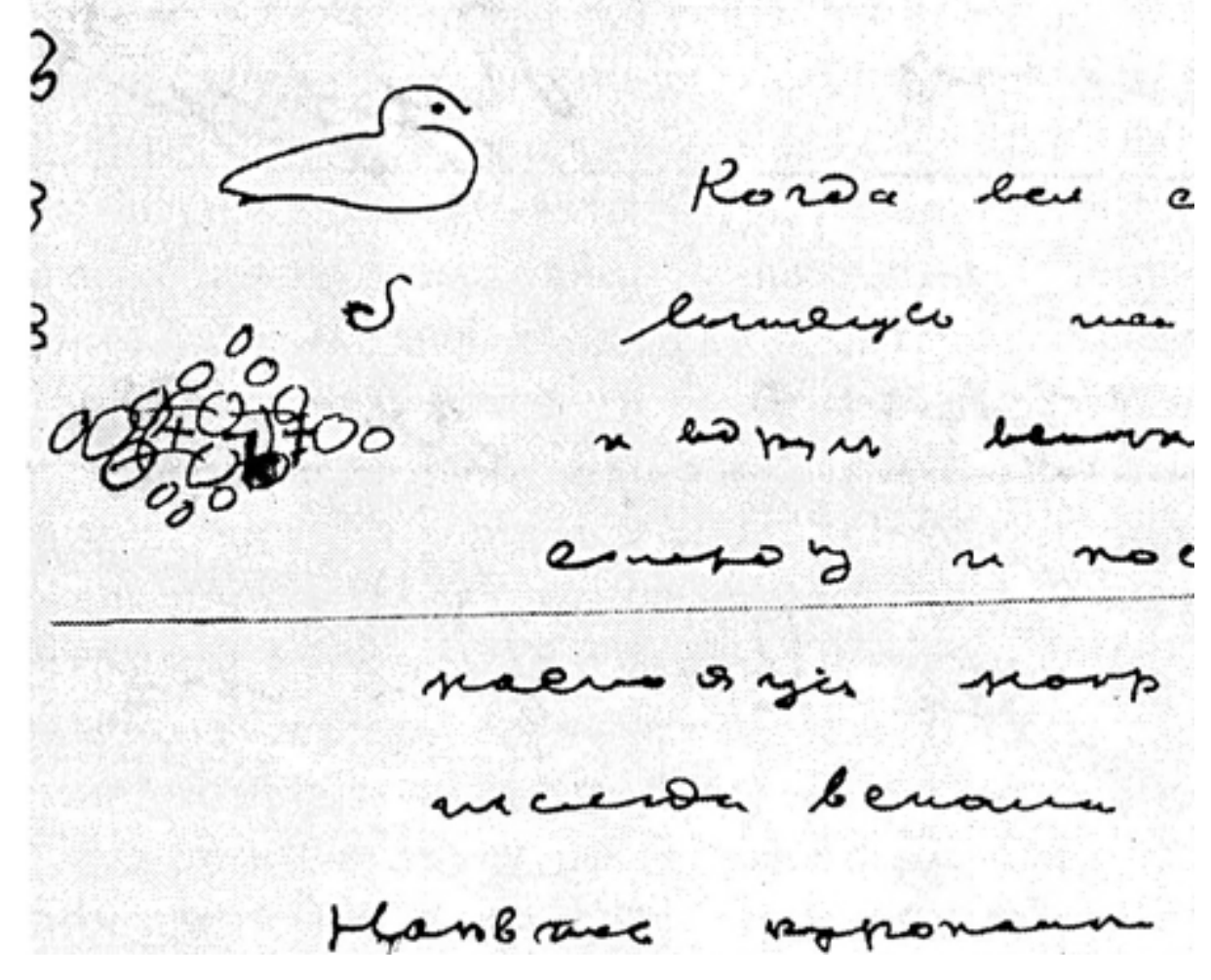

Fig. 3. Observações ornitológicas,

de Velimir Khlébnikov.

Fonte: Coletânea de obras em seis volumes

Ed. por R.V. Dugánov, v. 6, livro 1, p. 307-308

Fig. 4. Observações ornitológicas,

de Velimir Khlébnikov

Fonte: Coletânea de obras em seis volumes.

Ed. por R.V. Dugánov, v. 6, livro 1, p. 307-308,
Fig. 5. Observaçôes ornitológicas,

de Velimir Khlébnikov.

Fonte: Coletânea de obras em seis volumes.

Ed. por R.V. Dugánov, v. 6, livro 2, p. 244.

195 
e seus sonhos foram inspirados quando ele comparou a Terra a um pequeno animal da estepe, correndo de arbúsculo em arbúsculo. Ele descobriu a verdadeira classificação das ciências, ele associou tempo e espaço, ele fundamentou a geometria dos números. Ele descobriu o princípio eslavo, ele fundou um instituto para o estudo da vida pré-natal da criança. Ele descobriu o micróbio causador da paralisia progressiva, ele ligou e elucidou os princípios da química no espaço. Satisfeito de que deixassem uma página devotada a ele, a ele e a vários tantos.

Ele foi criança a ponto de supor que o seis viesse depois do cinco, e o sete depois do seis. Ele se atreveu inclusive a supor que, como regra geral, onde temos um e mais um, temos também três, cinco, e sete, e infinito $-\infty$.

Ademais, ele não expressou sua opinião sobre ninguém, ele a julgou pertencente à sua própria pessoa, reconheceu que 0 mais sagrado de qualquer dos direitos era o de ter uma opinião contrária.

1904

Estes dois textos foram escritos em 1904 e, embora sejam significativamente independentes, de modo aparentemente simultâneo. O primeiro, Deixe-os ler na lápide, é uma espécie de autoepitáfio (falando de si próprio na terceira pessoa), e o segundo, Cerca de cinco ou mais sentidos, é um exemplo de um julgamento analítico objetivo sobre questões científicas em si. Supõe-se que o primeiro texto, em sua própria concepção, tenha uma conexão significativa com outro fragmento de texto do caderno de Khlébnikov, escrito em 1904, denominado Dedicatória ao campesinato russo, no qual declara considerar os campesinos seus principais parceiros, a quem deve exclusivamente seu trabalho, uma vez que araram e semearam a terra para ele e assaram seu pão, enquanto ele lhes dedica um trabalho que seria uma fraca prova de seu dever, mas 
que demonstra também sua vastidão e irrelevância. 0 epitáfio cristianizado traz ao texto uma aura filosófica; há também a atribuição do significado de tecido cerebral ao tecido principesco. O impulso criativo parte de uma ideia de luta com sua própria visão, uma luta contra a visão positivista da estrutura antropocêntrica e hierárquica de todo o mundo vivo, e uma aproximação ao conceito ético de ortobiose, segundo o qual a pessoa se dota de uma prontidão racional para a morte, bem como se vê em pé de igualdade com as espécies biológicas. Pressupõe-se que Khlébnikov conhecesse a psicologia fisiológica de Wilhelm Wundt (1832-1920), substancializada pelo problema da sinestesia como uma interconexão de sensações físicas heterogêneas, problema que é estudado em conceitos e imagens da esfera matemática ${ }^{5}$.

\section{Cerca de cinco ou mais sentidos}

Cinco aspectos; há cinco deles, porém são insuficientes. Por que não dizer simplesmente: existe apenas um, mas um grandioso?

O padrão do pontilhado, quando preenches os espaços em branco, quando povoas o baldio desabitado?

Há certa grandeza, uma multiformidade infinitamente extensa, ${ }^{6} \mathrm{em}$ incessantes transformações, que, em relação aos nossos cinco sentidos, está na mesma posição que um espaço bidimensional contínuo está em relação a um triângulo, um círculo, uma oval, um retângulo.

Isto é, assim como um triângulo, um círculo, um octógono são partes de um plano, da mesma forma nossos sentidos de

5 Apresentação a partir das notas da Edição russa.

6 Ou "múltipla variedade estendida", termo de um trabalho do matemático alemão B. Riemann (1826-1866), Sobre as hipóteses que estão na base da geometria (Über die Hypothesen, welche der Geometrie zugrunde liegen), na coleção Sobre os fundamentos da geometria, traduzida e publicada em Kazan, em 1893, por ocasião do aniversário de N.I. Lobatchévski. (N. da E.) 
audição, visão, paladar e olfato são partes, lapsos fortuitos dessa grande multiformidade estendida.

Ele ergueu a cabeça leonina e nos encarou, mas seus lábios estavam cerrados.

Além disso, assim como pela contínua mutação de um círculo pode-se obter um triângulo, e o triângulo pode ser continuamente alterado para formar um octógono, e assim como de uma esfera no espaço tridimensional, pela via da variação contínua, pode-se obter um ovo, uma maçã, um chifre, um barrilete, apenas existem certas quantidades, variáveis independentes, que, à medida que alteram, transformam os sentidos das diversas sequências - por exemplo, o auditivo e visual ou olfativo -, um atravessa o outro.

De modo tal, alterando-se certos valores existentes, a cor azul de uma centáurea (refiro-me à sensação pura) pode ser incessantemente transformada por meio de regiões de rupturas desconhecidas pelos seres humanos e convertida no som de um cucar ou do choro de uma criança; assim estes passam a existir.

Durante essa variação contínua, cria-se certa diversidade de extensão, cujos pontos, salvo aqueles próximos ao primeiro e ao último, concernem a uma região de sensações desconhecidas, como se fossem de outro mundo. Tal diversidade já iluminou ao menos uma vez a mente de um homem agonizante, reluzindo como um relâmpago que reúne duas nuvens inchadas, ao combinar duas séries de experiências na consciência inflamada de um cérebro doente.

Pode ser que no instante pré-morte, ${ }^{7}$ quando tudo se apressa, quando todo o pânico e medo se dispersam, se precipitam, saltam barreiras, abandonam a esperança de salvaguardar a todos, a totalidade de muitas vidas individuais, e se inquieta sobre a própria, quando o que acontece na cabeça de um homem se assemelha ao que acontece em uma cidade submergida por ondas famintas de lava derretida, pode haver naquele instante pré-morte em cada cabeça humana uma celeridade

7 Tema retomado nos versos de 1915: "Antes da morte, a vida pisca novamente / Mas muito veloz e de outro modo" (Khlébnikov, 2000, p. 330). (N. da E.) 
assombrosa que se origina tal como o preenchimento de lacunas e valas, tamanha é a transgressão de formas e fronteiras. E quiçá, em toda consciência humana, numa celeridade assombrosa, uma sensação própria à ordem, A, transforma-se em uma sensação de ordem, B, e somente então, após tornar-se B, essa sensação perde celeridade e torna-se perceptível, à maneira como podemos captar os raios de uma roda somente quando a celeridade de sua rotação desacelera abaixo de certo limite. Tais celeridades nas quais as sensações fluem por esse espaço desconhecido são combinadas de tal modo que as sensações mais intimamente interligadas, positiva ou negativamente, à segurança de todo o ser se movem mais lentamente. $E$, desse modo, podem ser distinguidas com maior minudência e nuança. Aquelas sensações que têm menos a ver com questões existenciais transcorrem ligeiramente, sem permitir que a consciência se concentre nelas.

24 de novembro de 1904

No ano de 1913, nem Khlébnikov nem os seus pares descansaram; ele e Aleksiéi Krutchônikh passaram a viver em São Petersburgo, o que fez da cidade o novo local do movimento cubofuturista. Em março os cubofuturistas se aliaram à União da Juventude Pertersburguense, o que lhes trouxe auxílio financeiro, inclusive para a produção da obra Vitória sobre o Sol. De 1912 até o início de 1914, praticamente junto com o livro Um jogo no inferno, de Khlébnikov, saiu o livro de poesia de Krutchônikh, Amor à moda antiga, ilustrado por Mikhail Lariónov. Seguiram-se várias publicações, incluindo Uma bofetada no gosto do público, de 1913, além de uma segunda edição de Um jogo no inferno, no final desse mesmo ano, desta vez com ilustrações de Olga Rozánova e Kazímir

Malévitch. Houve o florescimento da amizade entre Khléb- 
nikov e Mikhail V. Matiúchin, que era referência na União e um de seus editores, bem como com Malévitch e Filônov, dois artistas admirados por Khlébnikov.

No outono de 1913, Tchukóvski deu uma palestra em Moscou e em São Petersburgo, A arte do futuro (poetas futuristas russos), que foi editada e publicada. A motivação principal da palestra era uma oposição aos inovadores locais da poesia democrática influenciada pela obra Folhas de relva, de Walt Whitman (1819-1892). Na ocasião, Tchukóvski foi contestado por D. Burliúk, A. Krutchônikh e V. Maiakóvski. Há coincidências lexicais na escrita de Krutchônikh e Khlébnikov ao se referirem a Tchukóvski nessa ocasião; ambos o chamaram de "comissário", porque em um de seus discursos um policial mantenedor da ordem fora lembrado da proibição pelo prefeito de ler em público versos dos futuristas.

\section{Observações polêmicas de 1913}

Vocês, ondas de imundice e vício, e tempestades de torpeza espiritual!

Vocês, Tchukóvskis, ${ }^{8}$ Iablonovskis! ${ }^{9}$ Saibam, guiamo-nos pelas estrelas, temos a mão firme no leme e nossa embarcação não teme seus cercos e assaltos. O pirata literário Tchukóvski, com o machado de Whitman, ${ }^{10}$ saltou em nosso convés duran-

8 Kórnei Ivánovitch Tchukóvski (1882-1969): crítico literário e autor de livros infantis que em seus artigos e palestras frequentemente se referia ao trabalho de Khlébnikov e opunha-se ao futurismo. (N. da E.)

9 Trata-se de uma das assinaturas de Serguéi Víktorovitch Potréssov (1870-1953), um jornalista moscovita, autor de vários artigos satíricos sobre o futurismo; citado por David Burliúk em seu texto de 1914, 0 vergonhoso pilar de um crítico russo. (N. da E.)

10 Refere-se a um texto de Tchukóvski sobre o poeta americano com o título provocador de 0 primeiro futurista. Maiores informações podem ser lidas no artigo de B. Lívchits, de 1919, 
te a tempestade para apoderar-se do lugar do timoneiro e dos tesouros da trajetória.

Mas você já não avista o cadáver dele flutuando nas ondas?

\section{II}

Ontem, o comissário de polícia Tchukóvski propôs que descansássemos; ${ }^{11}$ tirássemos uma soneca em uma cela com Whitman ${ }^{12}$ e uma certa -cracia. ${ }^{13}$ Mas os orgulhosos cavalos-de-prjeválski bufaram com desdém e se recusaram. $O$ freio dos citas, aquele que você vê no vaso Tchertomlyk - permaneceu suspenso no ar.

O texto a seguir trata-se de uma carta mesclada, escrita ao mesmo tempo em que ora a mensagem é dirigida a uma personagem sem nome, mas pertencente ao círculo do autor (provavelmente Nikolai Búrliuk), ora a Filippo Tommaso Marinetti (1876-1944), que visitara a Rússia a convite da Sociedade Internacional de Contatos Culturais. Na noite de $1^{\circ}$ de fevereiro de 1914, Khlébnikov apareceu na primeira palestra do futurista italiano, por ocasião de sua única visita à Rússia, para distribuir um folheto assinado por ele e pelo poeta Benedíkt Lívchits. Essa carta foi escrita por Khlébnikov no dia seguinte a esse episódio, quando o folheto em questão foi reimpresso no periódico jornalístico Notícias da Bolsa. A seguir, a reprodução do folheto: "Hoje, por razões pessoais, a colônia italiana no Nevá e alguns nativos caem aos pés de Marinetti, traindo a

Na cidadela da palavra revolucionária. (N. da E.)

11 (N. da T.)

12 (N. da E.)

13 Do gr. -kratía, as, do gr. krátos, eos-ous, "força"; "poder"; "autoridade"; "soberania"; "domínio"; "governo" (Dicionário Caldas Aulete). (N. da T.) 
arte russa em seus primeiros passos no caminho da liberdade e da honra, e inclinam a nobre altivez da Ásia sob o jugo da Europa. Aquelas pessoas que não aspiram à coleira de cavalo em torno do pescoço, como nos dias vergonhosos de Verhaeren e Max Linder, serão as silenciosas contempladoras de uma sombria façanha. Aquelas pessoas dotadas de vontade permanecerão de lado. Elas recordam-se das leis da hospitalidade, mas o arco delas está retesado, e a fronte está encolerizada. Forasteiro, lembre-se em que país você está! Carneiros da hospitalidade com os colarinhos de renda da servidão". ${ }^{14}$

Em princípios de 1914, Khlébnikov teria declarado que o gosto público de seu tempo usava o bigode gótico de Marinetti. Solicitava então que trouxessem esse gosto público à sua presença para que pudesse dar-lhe uma bofetada. No entanto, deve-se ter em mente a ambiguidade da atitude de Khlébnikov em relação ao líder do futurismo italiano em textos como $O$ trompete dos marcianos ${ }^{15}$.

Neste texto, Khlébnikov saúda os terráqueos e lhes adverte: "O cérebro humano até hoje estava pulando em três pernas (os três eixos de localização)! Como um lavrador, a cultivar o cérebro humano, refazemos este cãozinho dando-lhe uma quarta perna, a saber - o eixo do tempo. Oh, cãozinho coxo! Não mais torturarás nossos ouvidos com teu latido desagradável! As pessoas do passado não eram mais inteligentes que nós; elas acreditaram que as velas do Estado poderiam ser construídas apenas para os eixos do espaço. Nós, trajados apenas com uma capa de triunfos, começamos a construir uma aliança juvenil com a vela rente ao eixo do TEMPO, e advertimos de antemão que nossa dimensão é maior que a de Quéops, e que nossa incumbência é valente, majestosa e intransigente". E ele prossegue, dizendo que as questões futuristas estão em um espaço desabitado, em que o homem sequer chegou, "imperiosamente as marcaremos com ferrete na testa da Via Láctea, e na deidade circular dos negociantes - questões sobre como libertar o motor alado de sua via engordurada, o trem de carga

14 KHLÉBNIKOV, 2005, p. 345.

15 Baseado nas notas da edição russa. 
das gerações passadas. Deixe as faixas etárias se desprenderem e viverem apartadas! Desatrelamos os comboios atados à locomotiva de nossa ousadia - não há nada lá, salvo as lápides dos jovens....". Khlébnikov ainda clama pela rendição de todos os que estão mais próximos da morte do que do nascimento para que os jovens futuristas possam passar, acusa a geração passada de ter em suas próprias mãos a morte de seus ídolos - Púchkin e Liérmontov -, bem como do envio de homens do porte de Lobatchévski para atuar como professor em escola paroquial e do de Montgolfier para um hospício, e então questiona o que tal geração faria com os futuristas, que das fileiras humanas saem para as fileiras marcianas; e, entre os convidados sem direito a voto para o Conselho Marciano, Khlébnikov convoca H.G. Wells e Marinetti

\section{Seu tagarela sem talento! ${ }^{16}$}

Deixemos de lado a conduta bestial do dr. Kulbin. ${ }^{17}$ Este insensato de mente débil, este Lichard ${ }^{18}$ fiel, este tolo convencido, esperava que sua injúria obstinada maculasse o nome de alguém. Porém, na conduta bestial desse médico de renome, ouço uma voz italiana, que guia um polichinelo; então, com certo asco por esse negócio sujo, retorno para você as palavras de Kulbin: vilão, canalha. Ele é seu servo (o eslavo encontrou um senhor com um cnute). Defenda seu criado como alguém mais forte e mais igual a mim, e assuma a responsabilidade por sua conduta, carregando o peso dessas palavras: "vilão", "canalha", e aceite uma bofetada na cara, destinada a Marinetti, aquele vegetal italiano.

Entenda esta carta como quiser, junto ou separadamente de seus três amigos, mas aqui o Oriente lança um desafio ao arrogante Ocidente, pisoteando com desprezo os corpos dos devoradores de carniça.

Seu italiano Marinetti (discurso em Notícias da Bolsa ${ }^{19} \mathrm{n}^{\circ}$

19 Birjevýe Védomosti (Биржевьі́ ве́домости) foi um jornal pertersburguense diário, de 
13984) nos surpreende com sua agradável desenvoltura.

Não carecemos aceitar essas infusões de fora, porque nos lançamos ao futuro em 1905. O fato de Burliúks e Kulbins não terem percebido essa mentira indica que eles eram simuladores, e não autênticos.

A propósito, seu discurso no $n^{\circ} 13984$ é um monólogo de Griboiédov ${ }^{20}$ ("O francês de Bordeaux").

Amigo, você chegou atrasado à Rússia, você deveria ter vindo em 1814. Cem anos de erro no nascimento de um homem do futuro.

A corrida frenética da vida não se encerra para que um francês de Bordeaux intervenha a cada século.

Portanto, recorrendo à mesma linguagem que seu escravo Kulbin utilizou, você é um vilão e um canalha. Assim, um futurista honra o janota francês de Bordeaux. Adeus, seu vegetal!

Estou convencido de que em outros tempos nos encontraremos junto ao estrondo de canhões, em um duelo entre a coalizão ítalo-alemã e os eslavos, na costa da Dalmácia. Sugiro Dubróvnik como o lugar de encontro de nossos amigos.

P.S. Visto que seu amigo rejeitou qualquer responsabilidade por suas palavras, estou inteiramente convencido de que sua conduta corresponderá à dele e decidi não importuná-lo com quaisquer pedidos, pois considero o incidente encerrado.

A covardia é uma característica popular dos italianos; eles são comerciantes talentosos e fraudadores magistrais.

Minha carta não será um segredo.

De agora em diante, não tenho nada em comum com os membros da Guiléia. ${ }^{21}$

cunho político, econômico e literário liberal, uma gazeta mercantil com um boletim diário do mercado de ações, ativo de 1861 a 1879. (N. da T.)

20 Alusão ao poeta, dramaturgo, compositor, pianista e diplomata Aleksandr S. Griboiédov (1795-1829). (N. da T.)

210 poeta Aivchiu Benedíkt Naumóvitch (1886-1939), membro da Guiléia, confirmou e descreveu em suas memórias a atitude de vários representantes da arte de vanguarda russa em relação a Marinetti, bem como a posição da imprensa liberal russa ao cobrir a visita de um futurista estrangeiro. Naquela época, Khlébnikov havia encontrado em Lívchits um aliado para expressar sua própria posição social e cultural. Nas memórias do próprio Lívchits, 
2 de fevereiro 1914

V. Khlébnikov

B. Lívchits

A Nota autobiográfica a seguir foi provavelmente escrita na mesma época do preenchimento do formulário usado por Semión Afanássievitch Venguérov (1855-1920) para seu inacabado Dicionário crítico e bibliográfico de escritores russos; Khlébnikov participou e foi influenciado pelo famoso seminário de Venguérov sobre Púchkin. Esse formulário continha nove questões, entre elas, nome e local de nascimento, nome dos pais, formação educacional e religião, um delineamento das atividades literárias e alguma história da formação que indicasse qualquer influência intelectual e social; a esta pergunta, Khlébnikov respondeu: "Meu pai é um admirador de Darwin e Tolstói; é um grande conhecedor do reino das aves e as estudou a vida inteira..."; como evento marcante de sua vida, ele recordou um trabalho científico, Professor e aluno, em que chegara a conclusão de que os eventos semelhantes na história ocorrem a cada $365 \pm 48$ anos (a ponte para as estrelas) ${ }^{22}$.

\section{Nota autobiográfica}

Nasci em 28 de outubro de 1885, num campo de budistas nô-

este narra que ambos, ainda na gráfica, levaram um quarto de hora para obter a autorização de distribuição do folheto e Khlébnikov fez algumas alterações no texto, suavizando as expressões que the pareciam duras demais. Passada a palestra de Marinetti, David Búrliuk e V. Maiakóvski sairiam em turnê pela Crimeia, declarando a independência da nova arte russa; para Maiakóvski e outros, o futurismo era um movimento social nascido de uma grande cidade, destruindo, portanto, todo tipo de diferença nacional. Para eles, a poesia do futuro seria então cosmopolita. (N. da E.)

22 KHLÉBNIKOV, 2006, p. 240. Baseado nas notas da edição russa. 
mades $^{23}$ da Mongólia - na "sede do canado", na estepe ${ }^{24}$-, o fundo seco de uma parte desaparecida do mar Cáspio (o mar de quarenta nomes). Durante as viagens de Pedro, o Grande, no Volga, um dos meus antepassados ${ }^{25}$ serviu-o com um cálice de moedas de ouro oriundas de banditismo. Em minhas veias tenho sangue armênio (os alabovs) ${ }^{26}$ e sangue cossaco ${ }^{27}$ (os verbítskis), cuja linhagem especial manifesta-se no fato de que Prjeválski, ${ }^{28}$ Miklúka-Maklái ${ }^{29}$ e outros exploradores eram descendentes dos filhos de Sietch.

Pertenço ao local onde o Volga encontra o mar Cáspio (Sigái). Essa área, mais de uma vez ao longo dos séculos, manteve o equilíbrio da história russa e agitou a balança.

Fiz uma aliança matrimonial com a morte e, portanto, sou casado. Tenho vivido pelos rios Volga, Dniéper, Nevá, Moscou e Gorýn. ${ }^{30}$

\footnotetext{
23 Os Derbétys (Málye Derbéty, Calmúquia) pertencem à tribo mongol ocidental que migrou para as estepes no século XVl; praticam o lamaísmo, que surgiu no Tibete entre os séculos XIV e XV. (N. da E.)

24 Khlébnikov nasceu e viveu seus primeiros cinco anos nos arredores do mosteiro lamaísta da estepe da Calmúquia (território de Astracã). Vide poema, de 1909, em que Khlébnikov, vivente atado à natureza, escreveu: "Estava cercado por estepes, flores, camelos blaterando (...). Um mar de ovelhas cujas faces são uniformemente magras (...). Cinturão cossaco com gravuras bordadas (...). Aí está, homem, o que preencheu minh'alma" (Khlébnikov, 2000, p. 205). (N. da T.)
}

25 Acerca desse ancestral, segundo os historiadores locais, Pedro teria se encontrado em 1696 com P. Kúrotchkin, o mártir de Astracã, cujo parentesco com os Khlébnikov não foi comprovado. (N. da E.)

26 Origem por parte de mãe. (N. da E.)

27 Mais exatamente, de Zaporojskaia Sietch, espécie de república dos Estados cossacos. (N. da E.)

28 Nikolai M. Prjeválski (1839-1888), explorador e membro honorário da Academia de Ciências de São Petersburgo (1878), realizador de diversas explorações na Ásia, onde descobriu uma série de cadeias, bacias e lagos em regiões como as do platô tibetano. Catalogou plantas e animais; descreveu pela primeira vez um cavalo selvagem, o cavalo-de-prjeválski. (N. da E.)

29 Nikolai N. Miklúka-Maklái (1846-1888), explorador, antropólogo e biólogo que se opôs ao racismo e estudou a população indígena do sudeste; entre os anos de 1870-1880, viajou pela Ásia, Austrália e Oceania. (N. da E.)

30 Rio da Volýnia (Ucrânia). Os Khlébnikov residiam na antiga propriedade dos príncipes poloneses de Czartoryski. (N. da E.) 


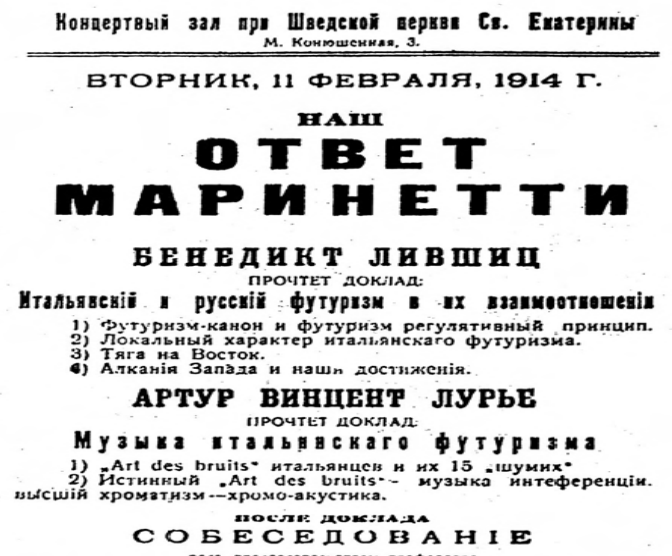

H. А. Б A

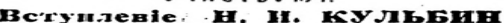

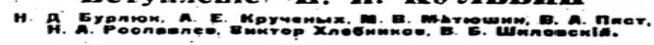

К полемике в связи с приездом Ф.-Т.Маринетти в Россию

346
Atravessando o istmo ${ }^{31}$ que une os reservatórios do Volga e do Liêna, fiz alguns punhados de água fluir para o oceano Ártico em vez de para o mar Cáspio.

Nadei no golfo de Sudák (três verstas ${ }^{32}$ ) e no Volga, em Ienotáevka. Montei cavalos indômitos em estábulos alheios. Exigi que o idioma russo fosse purificado ${ }^{33}$ do lixo de palavras estrangeiras, tendo feito tudo o que se pode esperar em dez páginas.

Publiquei Encantação pelo riso; dei às pessoas em $365 \pm 48$ os meios para prever o futuro, descobri a lei das gerações; Menina-Deus, onde povoei o passado russo com sombras radiantes; Amizade campesina; abri uma janela para as estrelas por entre as leis cotidianas da vida das pessoas.

Outrora fiz um apelo público ${ }^{34}$ aos sérvios e montenegrinos por ocasião da pilhagem da Bósnia-Herzegovina, um apelo que em parte se justificou alguns anos depois na Guerra dos

31 Vide, de Khlébnikov, Rázin às avessas, que reverencia o rebelde camponês do final do século XVII. (N. da E.)

32 Medida itinerária da Rússia, equivalente a 1067 metros. (N. da T.)

33 Vide Snegúrotchka; Khlébnikov representa essa personagem de conto de fadas segundo o princípio simbolista de estar imerso em um universo dramático-mitológico, de modo a resgatar pela via da língua e da cultura o universo do mito arcaico eslavo, trazendo seus deuses e heróis do passado sem passar pelo presente, já rumo ao futuro pelo viés da palavra que se autogera. (N. da T.)

34 Em Apelo aos eslavos, de 1908, saudando uma guerra santa pela unidade eslava, pelos direitos pisoteados dos eslavos, Khlébnikov escreveu: "Hoje, Lübeck e Dantzig nos consideram silenciados, nos testam - cidades com populações alemãs e nomes eslavos russos.

Seus corações não sentem nada pelos eslavos da Polábia? Nossas almas não foram 
Bálcãs e em defesa dos ugro-russos, ${ }^{35}$ a quem os alemães classificam como do reino vegetal.

O continente, despertando, entrega seu bastão às pessoas que vivem à beira-mar.

Em 1913 fui nomeado o grande gênio da atualidade, cuja patente guardo até agora.

Nunca prestei serviço militar

O motivo do texto a seguir de Khlébnikov foram as "Cartas de Amizade" escritas por dois estudantes japoneses e reimpressas pelo jornal moscovita Palavra Russa em 21 de setembro de 1916, extraídas do jornal de Tóquio Kokumin-Shimbun, cuja edição especial de 11 de setembro de 1916 anunciava uma viagem do príncipe herdeiro à Rússia em missão diplomática. Tal edição continha a matéria de um concurso juvenil cujo tema eram as relações russo-japonesas. A carta do vencedor, Sotaro Yamana, foi impressa em uma tradução para o russo, e a carta de Toya Mornta referia-se aos russos como pessoas do Oriente que viviam na Europa, e aos japoneses como pessoas

mortalmente envenenadas pela visão de Reicher, trajado de ferro, correndo sua lança pelos camponeses eslavos? Seus ultrajes são grandes e suficientes para embeber toda uma hoste de cavalos de vendeta - então os conduzimos do Don ao Dniéper, do Volga ao Vístula. (...) Os cavalos russos sabem como bater seus cascos nas ruas de Berlim. Nós não esquecemos isso. Ainda sabemos o que significa ser russo. (...) Abaixo os Habsburgo! Detenham os Hohenzollern!" (Khlébnikov, 2005, p. 197-198). (N. da T.)

35 Quem são os ugro-russos?, texto de 1913. "Chamados pelos húngaros de 'órochis', os ugro-russos, que se autodenominam russniaks ou russos, compreendem uma população de 500 a 700.000 habitantes e vivem em uma estreita faixa de terra entre a Hungria e a Galícia. No momento, estão sofrendo pressão simultânea da Santa Sé, esperançosa de adquirir novos filhos espirituais, e de Budapeste e Viena, que tentam engolir um grupo de pessoas que não são alemãs nem magiares. Representando a linha de frente da enchente eslava no sopé das terras magiares, imersos em seus trabalhos agrícolas, os ugro-russos nem sempre sabem que são objeto de um comércio vigoroso entre a Cidade Eterna e a capital dos Habsburgo, cujo meio de troca é sua antiga fé ortodoxa, à qual se referem como russos. Sob a pressão do catolicismo, plantado ora com violência por uma mão laica e militar, ora discreta e ardilosamente pela distorção dos livros litúrgicos, o povo ugro-russo está perdendo fortificações que pareciam inexpugnáveis..." (Khlébnikov, 2005, p. 68-69). (N. da T.) 
do Ocidente que viviam no Extremo Oriente. No texto havia a esperança de que em um futuro próximo o russo pudesse ser o unificador da cultura juvenil do Extremo Oriente e da cultura do Norte da Europa. Esses dois jovens japoneses teriam se dirigido ao jornal russo para que este fosse uma ponte entre os jovens do Japão e da Rússia. ${ }^{36}$

\section{Carta a dois japoneses}

Nossos amigos distantes! Sucedeu-me ler sua carta do jornal Kokumin-Shimbun e refleti se seria inoportuno responder-lhes. Decidi que não; então, por meio desta, apanho a bola e a lanço de volta para vocês, convoco-os a tomar parte do jogo de bola da geração mais jovem. Pois bem, vocês nos estenderam sua mão, por isso os cumprimentamos com o aperto de nossa mão, e agora as mãos dos jovens de dois países estão unidas em toda a Ásia, como o arco da aurora boreal. E nossos melhores desejos vão com o aperto de mão! Suponho que vocês não nos conheçam, mas ocorreu de parecer que estão escrevendo para nós e sobre nós. As mesmas opiniões sobre a Ásia que lhes ocorreram de modo tão inteligente e súbito, vieram às nossas cabeças. Pois acontece que, mesmo distantes uma da outra, as cordas começam a soar ainda que nenhum músico as tenha tocado, elas são despertadas por um som misterioso que ambas compartilham. E vocês ainda falam diretamente com os jovens de nosso país em nome de seus jovens. Essa é uma resposta muito coesa às nossas ideias sobre uma aliança mundial juvenil e os conflitos entre gerações. Afinal, as gerações caminham e falam de modos distintos. Compreendo melhor japoneses jovens falando o idioma arcaico do que alguns de meus compatriotas falando o russo moderno. Talvez muita coisa dependa do fato de que os jovens da Ásia nunca apertaram as mãos uns dos outros, e não se reuniram para trocar opiniões e para julgar assuntos comuns. Pois se existe um conceito de terra para os pais, então existe um para os filhos

36 Baseado nas notas da edição russa. 
e devemos salvaguardar os dois. Como parece, o objetivo consiste em não interferir na vida dos idosos, mas em construir nossa própria vida junto deles. Outra coisa compartilhada, que sentimos substancialmente, e sobre a qual nos calamos, é que a Ásia não é apenas uma terra do norte habitada por um polinômio de povos, mas é de fato uma espécie de miscelânea de caracteres antigos, dos quais deve surgir a palavra eu. Talvez ninguém ainda a tenha colocado por escrito; então, não é nosso destino comum, com alguma pena, colocá-la de imediato por escrito? Que a mão do escritor universal reflita sobre isso! Pois bem, vamos arrancar um pinheiro na floresta, mergulhá-lo no tinteiro do oceano e escrever nosso emblema-estandarte: Eu sou da Ásia. A Ásia tem vontade própria. Se o pinheiro partir, usaremos o monte Everest. Pois bem, tomemos as mãos uns dos outros, e tomemos as mãos de dois ou três hindus, e daiaques, e escalemos a partir do ano de 1916, como uma aliança dos jovens, reunidos não porque suas extensões de terra se avizinham, mas em virtude da irmandade de geração. Talvez possamos nos reunir em Tóquio. Afinal, somos egípcios contemporâneos, já que podemos falar em transmigração de almas, enquanto vocês costumam transparecer como os antepassados gregos. E quando o daiaque, um caçador de crânios, pregar em sua cabana o cartão postal de $A$ apoteose da guerra, de Vereshcháguin, ${ }^{37}$ ele se juntará a nós. Mas o maravilhoso é que vocês lançaram a bola e ela tocou nossos corações. Por essa razão, nos concederam o direito de dar o segundo passo, necessário para ambos os lados, mas irrealizável sem a amável iniciativa de vocês, porque com a devolução da bola, o jogo começa.

Cordialmente, caros amigos japoneses,

V. Khlébnikov

\footnotetext{
37 Vassíli Vereshcháguin (1842-1904) foi um cronista pictórico da guerra. A obra A apoteose da guerra tinha sido originalmente chamada de 0 triunfo de Tamerlão, referência ao conquistador da Ásia central que teria empilhado os crânios dos guerreiros mortos em batalha sob a forma de pirâmide. 0 pintor viajou pela Índia, Síria, Palestina e Ásia Central; tinha estúdios na Rússia, em Munique e em Paris, e sua obra foi amplamente exibida na Europa e nos Estados Unidos. Faleceu quando desenhava a bordo de um navio de guerra durante a Guerra Russo-Japonesa. (N. da T.)
} 
Textos de Velimir Khlébnikov em tradução anotada

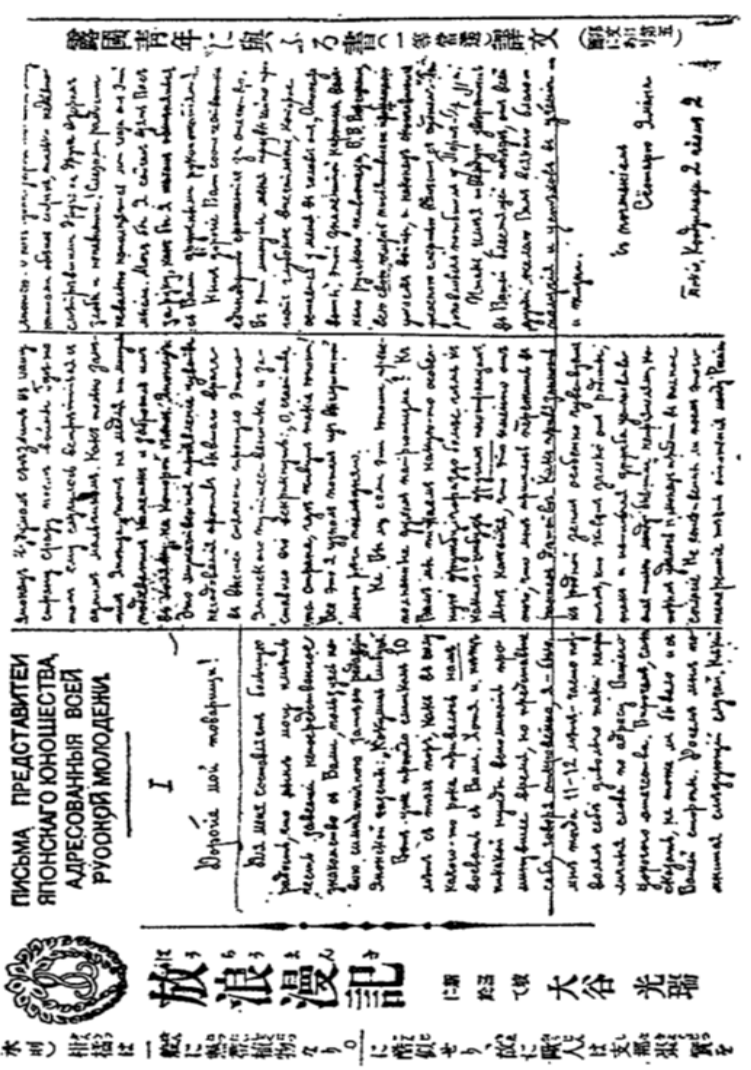




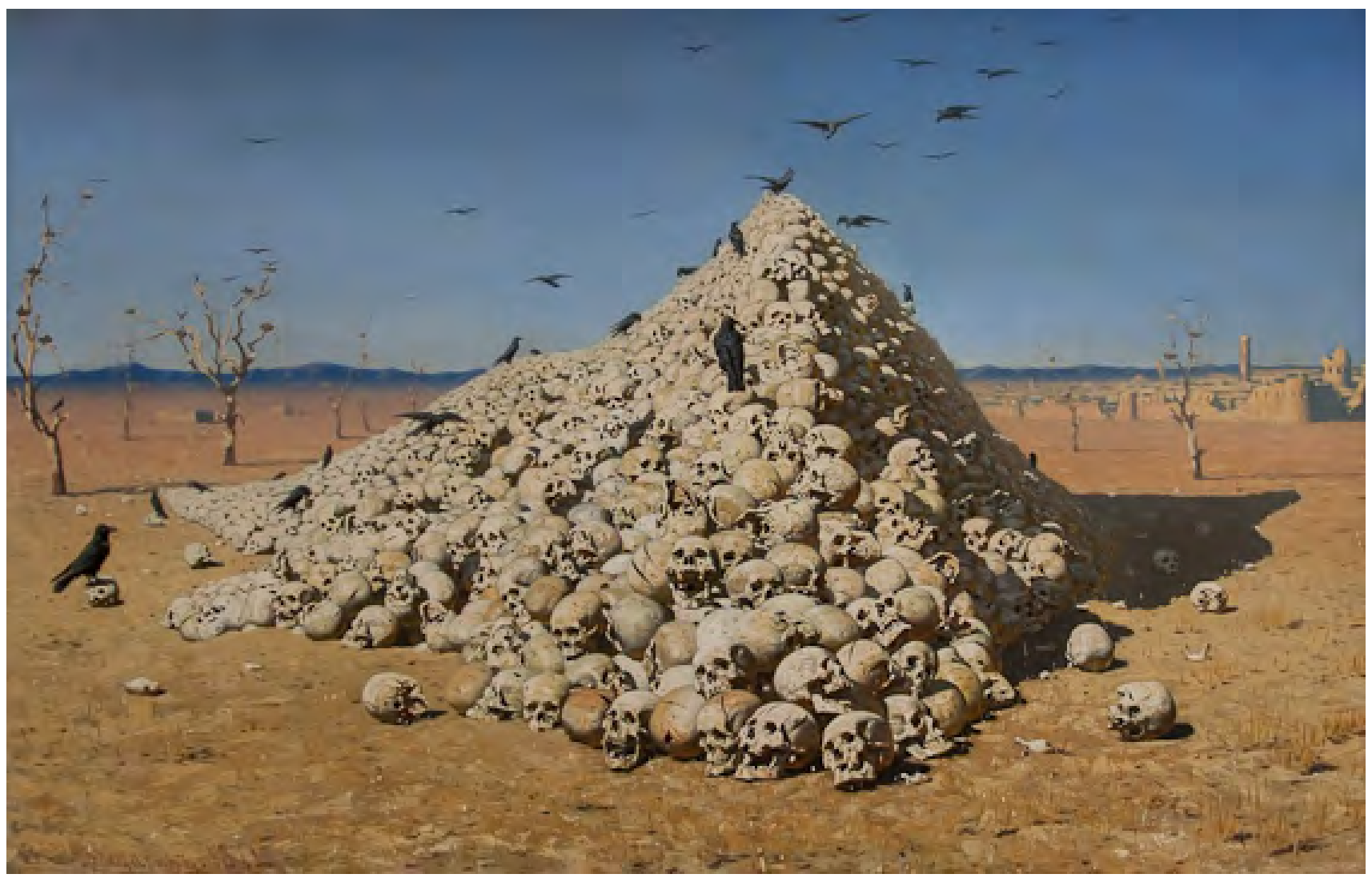

Eis aqui uma agenda de questões que poderíamos debater na primeira reunião de um congresso asiático:

1. Auxílio conjunto a inventores em sua luta com os compradores. Os inventores são próximos e compreensíveis a nós.

2. A fundação do primeiro Ensino Superior Futurista. ${ }^{38}$ Ele consistirá em vários (treze) locais alugados (por cem anos) de habitantes com propriedades no território disposto à beira-mar ou entre as montanhas, próximas aos vulcões extintos de Sião, da Sibéria, do Japão, do Ceilão, de Múrmansk, nas monta- 
nhas ermas; lá onde há dificuldade e não há de quem adquirir coisas, mas onde é fácil inventar. O radiotelégrafo unirá todos eles entre si, e as lições serão transmitidas pelo radiotelégrafo. Devemos ter nosso próprio radiotelégrafo. Comunicação por via aérea.

3. Em dois anos organizar ataques regulares contra as mentes dos habitantes desses territórios (não sobre seus corpos, apenas a suas mentes) para caçar suas ciências, golpeando-as com a flecha mortal das novas invenções.

4. Fundar o Diário Asiático para composições e invenções. Isso acelerará nosso vôo de gaviões do futuro. Os artigos serão impressos em qualquer idioma, radiotelegrafados a toda parte. O conteúdo será traduzido dentro de uma semana. Então ele se tornará uma chibata para a velocidade, se for diário e se estiver em mãos futuristas!

5. Refletir sobre a rota da linha férrea do Himalaia, com ramais em Suez e Malaca.

6. Não refletir sobre o classicismo grego, mas sim sobre o asiático (Vidjai, ${ }^{39}$ os Ronins, ${ }^{40}$ al-Masih al-Dajjal ${ }^{41}$ ).

7. Criar aves de rapina para lidar com pessoas que estejam se convertendo em coelhos. Nos rios, criar crocodilos. Examinar as capacidades intelectuais da geração mais velha.

8. Em nossas propriedades pitorescas arrendadas para uso temporário, instalar alojamentos de inventores, onde eles pos-

39 Campanha Vidjai; possível fonte de Khlébnikov: A história da humanidade. Ed. G. Guelmolt. Vol. II, São Petersburgo, 1903, p. 489 (История человечества. Г: Гельмольта. Т. II. СПб, 1903, C. 489). (N. da E.)

40 Um ronin era um guerreiro samurai do Japão feudal sem mestre ou senhor (daimio). (N. T.)

41 Possível fonte de Khlébnikov: Malóv, Evguêni A. Akhyr Zaman Kitabi: Doutrina maometana sobre o fim do mundo (Ахыр заман китаби: Мухаммеданское учение о кончине мира). Kazan, 1897. (Livro popular entre os tártaros de Kazan.) Nas lendas apócrifas muçulmanas, al-Masih ad-Dajjal é um tentador de pessoas que estabelecerá temporariamente seu reinado antes do fim do mundo (correspondência tipológica com o anticristo). Nessa doutrina, ele é uma figura do mal, o impostor que irá se passar pelo Messias antes do dia da ressurreição islâmica. Dajjal, no árabe, é "falso profeta", e al-Masih ad-Dajjal, com o artigo definido, significa "o impostor". 0 termo árabe para "falso messias", al-Masih ad-Dajjāl, vem do siríaco, Mšīā Daggālā, do vocabulário comum do Oriente Médio, antecede o Alcorão e advém da Peshitta, a Bíblia em aramaico. (N. da E.) 
sam viver de acordo com seu temperamento e gosto. Exigir que as cidades e vilarejos das cercanias os alimentem e os adorem.

9. Assegurar a transferência para nossas mãos daquela fração dos recursos que é nosso quinhão devido. A geração passada não aprendeu a extrair de si honradez suficiente em relação aos mais jovens, e, em muitos países, estes últimos levam uma vida de cães de Constantinopla.

10. De resto, concederemos à geração mais velha proceder como bem entender. O negócio dela é o regateio, a família e as posses. O nosso é a invenção, as artes, o conhecimento e a luta com ela.

11. Exterminar os idiomas sitiando seus segredos. A palavra não será mais para uso diário, mas somente para a palavra.

12. Intervir na arquitetura. Habitações transportáveis com ancoradouros para zepelins, gradeamento para as casas.

13. A linguagem dos números será o laurel dos jovens asiáticos.

Podemos designar cada ação e cada imagem com um número e, ao fazer com que um número seja avistado no vidro da luminária, comunicar-nos dessa forma. Para compilar tal dicionário para toda a Ásia (imagens e tradições de toda a Ásia) contamos com o trato pessoal entre os membros da Assembleia dos Jovens do Futuro. A linguagem dos números é especialmente adequada para telegramas de rádio. Conversa numérica. A mente se libertará do desperdício sem sentido de sua energia no discurso cotidiano.

Setembro de 1916 


\section{Referências bibliográficas}

\section{Dos textos:}

Khlébnikov, Velimir. Que assim leiam em minha lápide. In: Khlébnikov, Velimir. Coletânea de obras em seis volumes. Ed. por R.V. Dugánov. Volume 6, livro 1. Artigos (esboços). Trabalhos científicos. Apelos. Cartas abertas. Discursos 1904-1922. Moscou: IMLI RAN, 2005, p. 7-8.

Khlébnikov, Velimir. Cerca de cinco ou mais sentidos. In: Khlébnikov, Velimir. Coletânea de obras em seis volumes. Ed. por R.V. Dugánov. Volume 6, livro 1. Artigos (esboços). Trabalhos científicos. Apelos. Cartas abertas. Discursos 1904-1922. Moscou: IMLI RAN, 2005, p. 9-10.

Khlébnikov, Velimir. Observações polêmicas de 1913. In: Khlébnikov, Velimir. Coletânea de obras em seis volumes. Ed. por R.V. Dugánov. Volume 6, livro 1. Artigos (esboços). Trabalhos científicos. Apelos. Cartas abertas. Discursos 1904-1922. Moscou: IMLI RAN, 2005, p. 219.

Khlébnikov, Velimir. Seu tagarela sem talento! In: Khlébnikov, Velimir. Coletânea de obras em seis volumes. Ed. por R.V. Dugánov. Volume 6, livro 1. Artigos (esboços). Trabalhos científicos. Apelos. Cartas abertas. Discursos 1904-1922. Moscou: IMLI RAN, 2005, p. 222-223.

Khlébnikov, Velimir. Nota autobiográfica. In: Khlébnikov, Velimir. Coletânea de obras em seis volumes. Ed. por R.V. Dugánov. Volume 6, livro 2. Tabelas do destino. Pensamentos e notas. Cartas e outros. Materiais autobiográficos 1897-1922. Moscou: IMLI RAN, 2006, p. 243-244.

Khlébnikov, Velimir. Carta a dois japoneses. In: Khlébnikov, Velimir. Coletânea de obras em seis volumes. Ed. por R.V. Dugánov. Volume 6, livro 1. Artigos (esboços). Trabalhos científicos. Apelos. Cartas abertas. Discursos 1904-1922. Moscou: IMLI RAN, 2005, p. 252-256. 


\section{Das notas:}

Dicionário Caldas Aulete. Disponível em: <http://www.aulete. com.br/>. Acesso em: 29 dez. 2019.

Khlébnikov, Velimir. Coletânea de obras em seis volumes. Ed. por R.V. Dugánov. Volume 1. Textos literários. Autobiografia. Poesias 1904-1916. Moscou: IMLI RAN, 2000, p. 8; 205; 330.

Khlébnikov, Velimir. Coletânea de obras em seis volumes. Ed. por R.V. Dugánov. Volume 3. Poemas 1905-1922. Moscou: IMLI RAN, 2002, p. 422; 457; 488.

Khlébnikov, Velimir. Coletânea de obras em seis volumes.

Ed. por R.V. Dugánov. Volume 4. Poemas dramáticos. Dramas. Cenas 1904-1922. Moscou: IMLI RAN, 2003, p. 176.

Khlébnikov, Velimir. Coletânea de obras em seis volumes. Ed. por R.V. Dugánov. Volume 5. Poesia em prosa. Contos, novelas, ensaios, sagas 1904-1922. Moscou: IMLI RAN, 2004, p. 230; 411; 416; 428.

Khlébnikov, Velimir. Coletânea de obras em seis volumes. Ed. por R.V. Dugánov. Volume 6, livro 1. Artigos (esboços). Trabalhos científicos. Apelos. Cartas abertas. Discursos 1904-1922. Moscou: IMLI RAN, 2005, p. 352-440.

Khlébnikov, Velimir. Coletânea de obras em seis volumes. Ed. por R.V. Dugánov. Volume 6, livro 2. Tabelas do destino. Pensamentos e notas. Cartas e outros. Materiais autobiográficos 1897-1922. Moscou: IMLI RAN, 2006, p. 341-342.

Terras, Victor. A Karamazov Companion: Commentary on the Genesis, Language, and Style of Dostoevsky's Novel. Madison: University of Wisconsin Press, 2002.

Recebido em: 23/02/2020

Aceito em: 23/03/2020

Publicado em junho de 2020 